\title{
Effect of Contact Class Attendance on the Academic Success of Open Distance Learning Students in Advanced Certificate in Education Programs
}

\author{
J. M. van Zyl, E. J. Spamer, C. J. Els \\ North-West University, South Africa
}

\begin{abstract}
The article first explores open distance learning (ODL) as a delivery mode for professional teacher development programs in South Africa by comparing the ODL models of selected universities in developing, developed, and newly industrialized contexts. The article then reports on an empirical investigation conducted about the effect of contact class and vacation school attendance on the academic success of students $(n=1310)$ who wrote examination papers $(n=4931)$ for a variety of modules in four purposefully selected Advanced Certificate in Education (ACE) programs at the School of Continuing Teacher Education (SCTE) of the North-West University in South Africa. Descriptive statistics show the majority of students did not attend any contact classes or vacation schools, while still performing academically above average. Computing Spearman's rank-order correlations (r), no practically significant correlations were found between contact class and vacation school attendance and the academic success of students. However, ANOVA analyses reveal that it was beneficial for students to rather attend three contact sessions, than two or no contact sessions.
\end{abstract}

Keywords: Contact classes; Vacation schools; Class attendance; Academic success; Open distance learning

\section{Introduction}

One of the greatest challenges in South Africa since 1994 is the large number of unqualified and under-qualified practicing teachers within the National Department of Education. Since the majority of these teachers live and work in rural areas, open distance learning (ODL) is proving to be the most practical delivery mode for professional teacher development (Pandor, 2004; Van Zyl \& Spamer, 2010). Socio-economic, demographic and itinerant barriers, as well as family and occupational responsibilities hinder unqualified and under-qualified teachers from attending full-time university classes. Since 1993, in a momentous attempt to overcome these barriers, the School of Continuing Teachers Education (SCTE) at the North-West University dedicated itself to deliver quality professional development programs to teachers in rural areas. As from 2005, the SCTE utilizes ODL as delivering mode to provide unqualified and under-qualified teachers in rural areas the opportunity to enroll, throughout the year and from any geographic location in South Africa and Namibia, for accredited teachers' qualifications without halting their careers and leaving their schools and families to study on-campus. The ODL model of the SCTE provides students with the opportunity to attend, within a radius of $100 \mathrm{~km}$ from their work, non-compulsory supportive contact classes and vacation schools on scheduled dates throughout the year. Contact classes and vacation schools are presented by 
full-time lecturers and accredited part-time facilitators mainly on Saturdays and during school vacations to enable students to attend them without being meddlesome to their teaching responsibilities.

Currently, no South African research exists on the effect of contact class attendance on the academic success of ODL students. The coordination and presentation of contact classes at various rented venues throughout South Africa and Namibia demand a high monetary commitment from the SCTE and therefore necessitate an investigation into the effect of contact class attendance on the academic success of students in order to determine the feasibility of contact classes within the implemented ODL model. Accordingly, this paper reports on research conducted on the effect of contact class attendance on the academic success of students enrolled for Advanced Certificate in Education (ACE) programs at the SCTE.

\section{Orientation: “Open Distance Learning" Opposed to "Distance Education"}

According to Holmberg (1986), the first appearance of distance education can be traced back to a Swedish newspaper advertisement of 1833 which pioneered the opportunity to study composition through the post as medium. Initially, distance education was delivered primarily through correspondence courses via the post (Watkins, 1991). As early as 1881, the University of Illinois delivered Baccalaurean, Masters' and Doctorate degrees through off-campus programs based on the Oxford-Cambridge-London Model (Schlosser \& Simonson, 2002). Currently, distance education is broadly defined as the didactic preparation and presentation of study material, as well as the guidance and support of student learning, in which geographical distance is bridged between lecturer and student by means of at least one germane technical medium (Delling, 1987). Until recently, the terminology "distance education" was commonly used to describe this form of pedagogy.

Edwards (1995) and Picciano (2000) promote the terminology "open distance learning" (ODL), divergent from "distance education", as a new pedagogical method in a diverse and rapidly changing World. According to them, "distance education" entails mass produced course material intended for the mass market, in which curricula are developed and delivered from the viewpoint of lecturers. Opposed to this, the emphasis of ODL shifts from the mass market to the individual needs and expectations of students and markets, i.e. local contexts guide the development, implementation and deliverance of curricula. ODL epitomizes the opportunity for developing countries, such as South Africa and other African countries, to reach their national objectives.

According to the United Nations Educational Scientific and Cultural Organization (2002), increase in interest in ODL can be contributed to two main factors: (i) the growing need for continuing training and re-training of skills, and (ii) technological development and innovative communication which make teaching and learning over a distance increasingly easier via elearning. Accordingly, more and more universities around the world implement and use ODL as delivery mode, which usually entails both supportive contact classes and the progressive use of technology and e-learning. 


\section{Comparison between the ODL Models of Selected Universities in Developing and Developed Countries}

As part of a meta-analysis that compared the ODL models of purposefully selected universities in both developing and developed countries with regard to foundation and history, program delivery, contact classes, study groups, study material, examinations and e-learning, the researchers specifically focused on the role that traditional paper-based material, educational technology, e-learning and contact classes play in these models (compared cryptogrammically in Table 1).

Table 1. Cryptogrammic comparison between the ODL models of purposefully selected universities in developed, developing, and newly industrialized countries

\begin{tabular}{|c|c|c|c|c|c|}
\hline & $\begin{array}{c}\text { Uses } \\
\text { traditional } \\
\text { paper-based } \\
\text { study } \\
\text { material }\end{array}$ & $\begin{array}{l}\text { Uses various } \\
\text { types of } \\
\text { educational } \\
\text { technology } \\
\text { (CD, DVD, } \\
\text { radio, } \\
\text { satellite, TV, } \\
\text { e.g.) }\end{array}$ & $\begin{array}{l}\text { E-learning } \\
\text { (Internet- } \\
\text { based) }\end{array}$ & $\begin{array}{l}\text { Contact } \\
\text { classes }\end{array}$ & $\begin{array}{c}\text { Contact } \\
\text { classes non- } \\
\text { compulsory } \\
\text { (NC) } \\
\text { however, } \\
\text { some } \\
\text { contact } \\
\text { classes } \\
\text { compulsory } \\
\text { (V) } \\
\end{array}$ \\
\hline \multicolumn{6}{|l|}{ Developed countries } \\
\hline $\begin{array}{l}\text { Open University, Milton } \\
\text { Keynes, UK }\end{array}$ & $\sqrt{ }$ & $\mathrm{v}$ & $\sqrt{ }$ & $\sqrt{ }$ & $\mathrm{NCV}$ \\
\hline $\begin{array}{l}\text { Charles Sturt University, } \\
\text { Australia }\end{array}$ & $\sqrt{ }$ & $\mathrm{v}$ & $\sqrt{v}$ & $\sqrt{ }$ & $\mathrm{NC} v$ \\
\hline Linnaeus, Sweden & $\sqrt{ }$ & $\sqrt{ }$ & $\sqrt{ }$ & 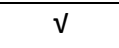 & NCV \\
\hline \multicolumn{6}{|l|}{ Developing Eastern countries } \\
\hline Bangladesh Open University & $\sqrt{ }$ & $\sqrt{ }$ & $\sqrt{ }$ & $\sqrt{ }$ & NC \\
\hline Universitas Terbuka, Indonesia & $\sqrt{ }$ & $\mathrm{V}$ & $\sqrt{ }$ & $\sqrt{ }$ & $\mathrm{NC}$ \\
\hline $\begin{array}{l}\text { Ghandi National Open } \\
\text { University (IGNOU), India }\end{array}$ & $\sqrt{ }$ & $\mathrm{v}$ & $\sqrt{ }$ & $\sqrt{ }$ & NCV \\
\hline \multicolumn{6}{|l|}{ Developing African countries } \\
\hline $\begin{array}{l}\text { National Open University of } \\
\text { Nigeria }\end{array}$ & $\sqrt{ }$ & $\mathrm{v}$ & $\sqrt{ }$ & $\sqrt{ }$ & NC V \\
\hline Open University of Tanzania & $\sqrt{ }$ & $\mathrm{v}$ & & $\sqrt{ }$ & $\sqrt{ }$ \\
\hline Makerere University, Uganda & $\mathrm{v}$ & $\mathrm{v}$ & $\mathrm{v}$ & $\sqrt{ }$ & NC V \\
\hline \multicolumn{6}{|l|}{$\begin{array}{l}\text { South Africa as a newly } \\
\text { industrialised country (NIC) }\end{array}$} \\
\hline $\begin{array}{l}\text { University of South Africa } \\
\text { (UNISA) }\end{array}$ & $\sqrt{ }$ & $\mathrm{v}$ & $\sqrt{ }$ & $\sqrt{ }$ & NCV \\
\hline University of Pretoria & $\sqrt{ }$ & $\mathrm{v}$ & $\mathrm{v}$ & $\mathrm{V}$ & $\mathrm{NCV}$ \\
\hline $\begin{array}{l}\text { School of Continuing Teacher } \\
\text { Education, North-West } \\
\text { University }\end{array}$ & $\sqrt{ }$ & $\sqrt{ }$ & $\sqrt{v}$ & $\mathrm{~V}$ & NC \\
\hline
\end{tabular}


Four groups of universities that use ODL models were purposefully selected: (i) universities in developed countries, i.e. the Open University in the United Kingdom, the Charles Sturt University in Australia, and Linnaeus in Sweden; (ii) universities in developing Eastern countries, i.e. the Bangladesh Open University, Universitas Terbuka in Indonesia, and the Ghandi National Open University in India; (iii) universities in developing African countries, i.e. the National Open University of Nigeria, the Open University of Tanzania, and the Makerere University in Uganda; and (iv) universities in South Africa as a newly industrialized country, i.e. the University of South Africa, the University of Pretoria, and the North-West University's SCTE.

As from 2011, South Africa is listed as a Newly Industrialised Country (NIC) by the International Monetary Fund (2011). NICs are characterized by: (i) an economy that has not yet reached $1^{\text {st }}$ World status but has, in a macroeconomic sense, outpaced it's developing counterparts, (ii) rapid economic growth that is export-oriented, (iii) an increasingly open-market economy that allows free trade, (iv) ongoing industrialization, (v) migration of populations to cities to work in industries, factories and mines, (vi) increased social freedom and civil rights, etc. (International Monetary Fund, 2011). All these universities deliver well established and reputable ODL programs to large numbers of students Worldwide. For example, both the Open University in Milton Keynes and the Bangladesh Open University have more than 200,000 students enrolled for ODL programs, the Universitas Terbuka in Indonesia swank with 350,000 enrolled students and 700 available courses to opt from, while Nigeria shines out with some of the most modern and largest ODL unites in Africa.

From Table 1 it becomes clear that contact classes form an integral part of ODL models Worldwide. The Bangladesh Open University and the Universitas Terbuka in Indonesia is the only purposefully selected universities in which all contact classes are non-compulsory. In the other universities, the majority of contact classes are non-compulsory, while some contact classes are compulsory and prerequisite for specific modules. At the Open University of Tanzania all contact classes are compulsory and considered an essential component of effective teaching and learning. Although these universities regard contact classes as an important supportive and even indispensable component of ODL, no research could be found on the effect of contact class attendance on the academic success of ODL students. However, some related studies could be found, mostly focusing on the effect of contact classes on both on-campus and off-campus students, the effect of contact classes on social interaction, and the effect of contact classes on learning experiences.

\section{Related Research Studies}

Shachar (2008) shows that a variety of research studies comparing face-to-face learning with distance learning report contradicting findings. In a meta-analysis of 232 studies conducted between 1985 and 2002 which compared traditional classroom instruction with distance education, Bernard, Abrami, Lou, Borokhovski, Wade, Wozney, Wallet, Fiset and Huang (2004) found distance education to be more effective in many cases. Accordingly, Taylor (2006) also found that face-to-face interaction between lecturer and student in a contact class situation is not a prerequisite for effective teaching and learning. The effectiveness of face-to-face contact sessions was compared with online learning programs by Solimeno, Mebane, Tomai and Francescato (2008). They found that online methods create innovative possibilities in terms of learning problems and time management. The study of Hui, Crowcroft and Yoneki (2008) found education over a distance, which incorporate technology, is more effective for 
students to enhance their vocabulary than contact classes. On the other hand, contact classes seem to be more effective for students to enhance their listening skills, than distance education. Synchronic application of performance outcomes prefers classroom education, while asynchronic application of performance outcomes prefers distance education (Bernard, et al., 2004).

If one looks at the few research findings on the effect of contact classes on social interaction, Simpson (2002) found that student dropout rate increases with $20 \%$ in distance education as a result of educational isolation where students do not attend contact classes. On the other hand, Lobel and Neubauer (2005) compared students who attend face-to-face contact classes with a group of students who study via a web platform. Both student groups were educated by the same lecturer. They found that the online group was more actively involved in virtual classroom discussions and less afraid to share their opinion than the students who attended face-to-face contact classes. Furthermore, the social interaction of the online group developed into a specific group identity, something that the researchers could not detect amongst the students who attended contact classes. In a large quantitative study, Jahng, Krug and Zhang (2007) confirm that students who study online courses perform significantly better than students who attend traditional face-to-face contact classes.

In a research study conducted on the effect of contact classes on the learning experience of students, Deka and McMurry (2006) found distance education students are less successful in examinations than students who attend contact classes. They also found that reading comprehension and reading rate are indicative of the examination success of students who attend face-to-face contact classes.

Exploring the literature it becomes clear that in spite of various related studies on contact classes for distance education, no research studies could be found, internationally nor nationally, that specifically investigate the effect of contact class attendance on the academic success of ODL students. The current investigation aims to bridge this gap with an empirical investigation into the effect of contact class attendance on the academic success of ODL students in Advanced Certificate in Education (ACE) programs.

\section{Research Paradigm, Design and Methodology}

This objective quantitative research study falls within the Radical Structuralism metaparadigm. The Radical Structuralism approach explores social phenomena with quantitative research design and methodology in which practically significant correlations and differences are empirically computed and analyzed between variables (Burrell \& Morgan, 1979). This approach was used to empirically investigate the effect of contact class attendance on the academic success of ODL students enrolled for Advanced Certificate in Education (ACE) programs at the SCTE of the North-West University in South Africa.

\section{Demographics of Sample}

For the purpose of this investigation, data (final module marks and attendance registers) of students who wrote examination in the following ACE programs was purposefully selected: (i) Mathematics Education; (ii) Learner Support; (iii) Foundation Phase; and (iv) Geography. 
Table 2. Frequencies of examination papers written during October 2009 for various modules per ACE program

\begin{tabular}{|l|c|c|}
\hline $\begin{array}{l}\text { Advanced Certificate in Education } \\
\text { (ACE) programs }\end{array}$ & $\begin{array}{c}\text { Frequencies examination } \\
\text { papers written for } \\
\text { various modules }\end{array}$ & $\begin{array}{c}\text { \% Frequencies } \\
\text { examination papers } \\
\text { written for various } \\
\text { modules }\end{array}$ \\
\hline Mathematics Education & 1298 & 26.32 \\
\hline Learner Support & 1923 & 39.01 \\
\hline Foundation Phase & 1657 & 33.60 \\
\hline Geography & 53 & 1.07 \\
\hline Total & $\mathbf{4 9 3 1}$ & $\mathbf{1 0 0 \%}$ \\
\hline
\end{tabular}

Table 2 shows the frequencies of examination papers written during October 2009 for various modules per ACE program. In total, four thousand nine hundred and thirty one $(n=4931)$ examination papers were written by one thousand three hundred and ten $(n=1310)$ students for various modules in the four ACE programs. The student population is representative of gender, as well as diverse cultural, language and age groups. The most examination papers were written for modules in the Learner Support ACE program $(n=1923)$, while only fifty three $(n=53)$ examination papers were written for modules in the Geography ACE program.

Table 3. Frequencies of examination papers written during October 2009 for various modules in the four ACE programs per South African Province

\begin{tabular}{|l|c|c|}
\hline $\begin{array}{l}\text { South African Provinces } \\
\text { (main geographical regions) }\end{array}$ & $\begin{array}{c}\text { Frequencies of } \\
\text { examination papers } \\
\text { written for various } \\
\text { modules }\end{array}$ & $\begin{array}{c}\text { \% Frequencies } \\
\text { examination papers } \\
\text { written for various } \\
\text { modules }\end{array}$ \\
\hline Eastern Cape & 1099 & 22.29 \\
\hline Free State & 147 & 2.98 \\
\hline Gauteng & 191 & 3.87 \\
\hline KwaZulu-Natal & 590 & 11.97 \\
\hline Limpopo & 829 & 16.81 \\
\hline Mpumalanga & 1075 & 21.80 \\
\hline North-West & 432 & 8.76 \\
\hline Northern Cape & 255 & 5.17 \\
\hline Western-Cape & 276 & 5.60 \\
\hline Unspecified & 37 & 0.75 \\
\hline Total & $\mathbf{4 9 3 1}$ & $\mathbf{1 0 0 \%}$ \\
\hline
\end{tabular}

Table 3 provides the frequencies of examination papers written for various modules in the four ACE programs at 68 examination centers throughout the nine Provinces (main geographical regions) of South Africa. Most examination papers were written in the Eastern Cape $(n=1099)$ and Mpumalanga $(n=1075)$ Provinces. 


\section{Data Mining and Empirical Analysis}

The two main variables identified for the empirical analysis are: (i) contact class attendance and (ii) academic success (final module marks). The North-West University's student record system was used to obtain an electronic dataset containing the final module marks (accumulate from module assignment and examination marks) of students who wrote examination papers during October 2009 for the various modules in the four purposefully selected ACE programs. The attendance registers of contact centers were checked to see how many non-compulsory contact opportunities (out of six contact classes and one vacation school) these students attended during the period April to September 2009 for the various modules in which they wrote examination papers. The attendance register data was captured and included as part of the dataset. The statistical software SPSS (2007) was used to perform the empirical analyses. Descriptive statistics were computed to explore the sample demographics (Tables 2 and 3), as well as to calculate contact class and vacation school attendance frequencies (presented in Tables 4 and 5 below). Cramer's effect sizes (V) were calculated using two-way tables (Tables 6 to 9) in order to search for practical significant discrepancies, if any, between the contact class and vacation school attendance for modules within each of the four ACE-programs. Inferential statistics were then computed to search for practically significant Spearman's rank-order correlations ( $r$-values) between academic success (final module marks) and contact class attendance (presented in Table 10 below). In order to establish if it was more beneficial for students' academic success to attend three contact sessions rather than one, two or no contact sessions, a one way ANOVA association analysis (Cohen's d-values) was preformed (presented in Table 11 below).

\section{Findings}

\section{Contact Class and Vacation School Attendance Frequencies}

Table 4 provides the contact class attendance frequencies and Table 5 the vacation school attendance frequencies of the total sample of examination papers written $(n=4931)$ by students $(n=1310)$ for various modules in the four ACE programs.

Table 4. Contact class attendance frequencies of examination papers written for various modules in the four ACE programs

\begin{tabular}{|c|c|c|c|c|}
\hline $\begin{array}{c}\text { Number of } \\
\text { contact } \\
\text { classes } \\
\text { attended }\end{array}$ & $\begin{array}{c}\text { Frequencies of } \\
\text { examination } \\
\text { papers written } \\
\text { for various } \\
\text { modules }\end{array}$ & $\begin{array}{c}\text { \% Frequencies } \\
\text { examination } \\
\text { papers written } \\
\text { for various } \\
\text { modules }\end{array}$ & $\begin{array}{c}\text { Mean scores } \\
\text { of academic } \\
\text { success } \\
\text { (final marks) }\end{array}$ & $\begin{array}{c}\text { Standard } \\
\text { deviation } \\
\text { of academic } \\
\text { success } \\
\text { (final marks) }\end{array}$ \\
\hline 0 & 3999 & $81.10 \%$ & 56.27 & 15.07 \\
\hline 1 & 864 & $17.52 \%$ & 58.28 & 13.43 \\
\hline 2 & 65 & $1.32 \%$ & 56.11 & 15.15 \\
\hline 3 & 3 & $0.06 \%$ & 63.67 & 15.04 \\
\hline 4 & - & - & - & - \\
\hline 5 & - & - & - & - \\
\hline 6 & - & - & - & - \\
\hline Total & $\mathbf{4 9 3 1}$ & $\mathbf{1 0 0 \%}$ & $\mathbf{5 6 . 6 3}$ & $\mathbf{1 4 . 8 1}$ \\
\hline
\end{tabular}


Table 5. Vacation school attendance frequencies of examination papers written for various modules in the four ACE programs

\begin{tabular}{|c|c|c|}
\hline $\begin{array}{c}\text { Vacation school } \\
\text { attendance }\end{array}$ & $\begin{array}{c}\text { Frequencies examination } \\
\text { papers written for various } \\
\text { modules }\end{array}$ & $\begin{array}{c}\text { \% Frequencies examination } \\
\text { papers written for various } \\
\text { modules }\end{array}$ \\
\hline 0 & 4538 & $92.03 \%$ \\
\hline 1 & 393 & $7.97 \%$ \\
\hline Total & 4931 & $100 \%$ \\
\hline
\end{tabular}

It is clear from the results that the vast majority of students $(81.1 \%)$ who wrote examination papers for various modules did not attend any contact classes $(n=3999)$, while $17.52 \%(n=$ 864 ) attended one contact session, $1.32 \%(n=65)$ attended two contact sessions, and only $0.06 \%(n=3)$ attended three contact sessions. No students attended four, five or six contact sessions for any of the modules written. Further analysis showed that the contact class attendance rate for modules in the Mathematics Education ACE program was the lowest $(86 \%$ of students who wrote examination papers for modules in this program did not attend any contact classes).

The vast majority of students $(92.03 \% ; n=4538)$ who wrote examination papers for various modules in the four ACE programs also did not attend the vacation school presented during July 2009 , while only $7.97 \%(n=393)$ attended the vacation school. The percentage frequency vacation school attendance was therefore even lower than the percentage frequency contact class attendance. The vacation school attendance rate for modules in the Learner Support ACE program was the lowest ( $92.9 \%$ of students who wrote examination papers for modules in this program did not attend the vacation school).

Most students who wrote examination papers for modules in the four ACE programs preformed above average. The average pass rate of the 4931 examination papers written for various modules during October 2009 was $77.29 \%(n=3811)$. The highest average pass rate for program modules was $81.14 \%$ for the Geography ACE program. A small difference was found between the average pass rate of modules in which students attended one or more contact classes $(57.45 \%)$ and the average pass rate of modules in which students did not attend any contact classes (54.69\%). Thus, from the descriptive statistics it already seems that contact session attendance has little or no impact on the academic success of students. However, the researchers decided to perform inferential statistics (correlations) in order to compute the effect of contact class attendance on the academic success of students. 
Table 6. Two-Way Table of the Number of Students Who Attended Contact Classes and Vacation Schools Within the ACE-Program Mathematics Education, and Who Wrote Examination During October 2009

\begin{tabular}{|c|c|c|c|c|c|c|c|c|c|c|c|c|c|c|c|c|c|}
\hline & \multicolumn{8}{|c|}{ Contact class attendance } & \multicolumn{4}{|c|}{ Vacation school attendance } & \multicolumn{4}{|c|}{ Pass / fail } \\
\hline & & \multicolumn{2}{|c|}{$\begin{array}{l}\text { No contact } \\
\text { class }\end{array}$} & \multicolumn{2}{|c|}{$\begin{array}{l}1 \text { contact } \\
\text { class }\end{array}$} & \multicolumn{2}{|c|}{$\begin{array}{c}2 \text { contact } \\
\text { classes }\end{array}$} & \multicolumn{2}{|c|}{$\begin{array}{c}3 \text { contact } \\
\text { classes }\end{array}$} & \multicolumn{2}{|c|}{$\begin{array}{l}\text { No vacation } \\
\text { school }\end{array}$} & \multicolumn{2}{|c|}{$\begin{array}{c}\text { Vacation } \\
\text { school }\end{array}$} & \multicolumn{2}{|c|}{$\begin{array}{c}\text { Fail final module } \\
\text { mark }<50\end{array}$} & \multicolumn{2}{|c|}{$\begin{array}{l}\text { Pass final module } \\
\text { mark }>50\end{array}$} \\
\hline \multirow{13}{*}{ 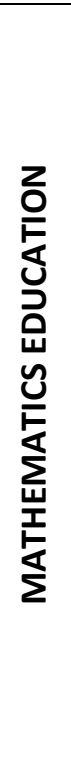 } & MODULES & $n$ & $\%$ & $n$ & $\%$ & $n$ & $\%$ & $\mathrm{n}$ & $\%$ & $n$ & $\%$ & $n$ & $\%$ & $n$ & $\%$ & $n$ & $\%$ \\
\hline & NDWK522 & 100 & 97.1 & 3 & 2.9 & - & - & - & - & 103 & 100 & - & - & 6 & 5.8 & 97 & 94.2 \\
\hline & NWPK511 & 133 & 85.8 & 18 & 11.6 & 3 & 1.9 & 1 & 0.7 & 133 & 83.7 & 22 & 13.8 & 22 & 14.2 & 133 & 85.8 \\
\hline & ORLK521 & 74 & 83.2 & 15 & 16.9 & - & - & - & - & 85 & 95.5 & 4 & 4.5 & 26 & 29.2 & 63 & 70.8 \\
\hline & NWPK521 & 85 & 84.2 & 16 & 15.8 & - & - & - & - & 100 & 99.0 & 1 & 0.9 & 26 & 25.7 & 75 & 74.3 \\
\hline & FSET511 & 110 & 79.1 & 28 & 20.1 & 1 & 0.7 & - & - & 117 & 84.2 & 22 & 15.8 & 34 & 24.5 & 105 & 75.6 \\
\hline & EUCE511 & 123 & 91.8 & 11 & 8.2 & - & - & - & - & 131 & 97.8 & 3 & 2.2 & 4 & 2.9 & 130 & 97.0 \\
\hline & ORLK511 & 105 & 78.9 & 24 & 18.1 & 4 & 3.0 & - & - & 118 & 88.7 & 15 & 11.3 & 46 & 34.6 & 87 & 65.4 \\
\hline & EDFM523 & 88 & 88.0 & 12 & 12.0 & - & - & - & - & 93 & 93.0 & 7 & 7.0 & 40 & 40.0 & 60 & 60.0 \\
\hline & HIVA521 & 105 & 91.3 & 10 & 8.7 & - & - & - & - & 108 & 93.9 & 7 & 6.1 & 20 & 17.4 & 95 & 82.6 \\
\hline & NWPK512 & 143 & 85.1 & 21 & 12.5 & 4 & 2.4 & - & - & 145 & 86.3 & 23 & 13.7 & 56 & 33.3 & 112 & 66.7 \\
\hline & NWPK522 & 63 & 82.9 & 13 & 17.1 & - & - & - & - & 67 & 89.3 & 8 & 10.7 & 34 & 44.7 & 42 & 55.3 \\
\hline & & 1129 & & 171 & & 12 & & 1 & - & 1200 & & 112 & & 314 & 23.9 & 999 & 76.1 \\
\hline & & \multicolumn{4}{|c|}{$V=0.1$} & \multicolumn{4}{|c|}{$p=0.0000$} & \multicolumn{2}{|c|}{$V=0.2$} & \multicolumn{2}{|c|}{$p=0.0000$} & \multicolumn{4}{|c|}{$p=0.0000$} \\
\hline
\end{tabular}


Table 7. Two-Way Table of the Number of Students Who Attended Contact Classes and Vacation Schools Within the ACE-Program Learner Support, and Who Wrote Examination During October 2009

\begin{tabular}{|c|c|c|c|c|c|c|c|c|c|c|c|c|c|c|c|c|c|}
\hline & \multicolumn{8}{|c|}{ Contact class attendance } & \multicolumn{4}{|c|}{ Vacation school attendance } & \multicolumn{4}{|c|}{ Pass / fail } \\
\hline & & \multicolumn{2}{|c|}{$\begin{array}{l}\text { No contact } \\
\text { class }\end{array}$} & \multicolumn{2}{|c|}{$\begin{array}{l}1 \text { contact } \\
\text { class }\end{array}$} & \multicolumn{2}{|c|}{$\begin{array}{c}2 \text { contact } \\
\text { classes }\end{array}$} & \multicolumn{2}{|c|}{$\begin{array}{l}3 \text { contact } \\
\text { classes }\end{array}$} & \multicolumn{2}{|c|}{$\begin{array}{l}\text { No vacation } \\
\text { school }\end{array}$} & \multicolumn{2}{|c|}{$\begin{array}{c}\text { Vacation } \\
\text { school }\end{array}$} & \multicolumn{2}{|c|}{$\begin{array}{l}\text { Fail final module } \\
\text { mark }<50\end{array}$} & \multicolumn{2}{|c|}{$\begin{array}{l}\text { Pass final module } \\
\text { mark }>50\end{array}$} \\
\hline \multirow{14}{*}{ 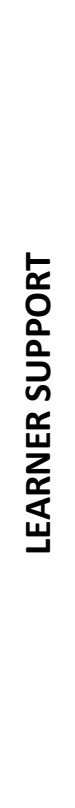 } & MODULES & n & $\%$ & $\mathbf{n}$ & $\%$ & $\mathrm{n}$ & $\%$ & $\mathrm{n}$ & $\%$ & $\mathrm{n}$ & $\%$ & $\mathrm{n}$ & $\%$ & $n$ & $\%$ & $\mathrm{n}$ & $\%$ \\
\hline & ORLK521 & 124 & 89.9 & 13 & 9.4 & 1 & 0.7 & - & - & 131 & 94.9 & 7 & 5.1 & 32 & 23.2 & 106 & 76.8 \\
\hline & ORAK511 & 133 & 77.8 & 35 & 20.5 & 3 & 1.8 & - & - & 146 & 85.4 & 25 & 14.6 & 29 & 16.9 & 142 & 83.0 \\
\hline & FSET511 & 141 & 75.4 & 43 & 22.9 & 3 & 1.6 & - & - & 161 & 86.1 & 26 & 13.9 & 49 & 26.2 & 138 & 73.8 \\
\hline & LSSH528 & 104 & 83.9 & 16 & 12.9 & 4 & 3.2 & - & - & 124 & 100.0 & - & - & 8 & 6.5 & 116 & 93.6 \\
\hline & LSED518 & 97 & 71.3 & 37 & 27.2 & 2 & 1.5 & - & - & 136 & 100.0 & - & - & 46 & 33.8 & 90 & 66.2 \\
\hline & EUCE511 & 139 & 80.4 & 32 & 18.5 & 2 & 1.2 & - & - & 172 & 99.4 & 1 & 0.6 & 8 & 4.6 & 165 & 95.4 \\
\hline & LSDL528 & 122 & 85.9 & 18 & 12.7 & 2 & 1.4 & - & - & 132 & 92.9 & 10 & 7.0 & 6 & 4.2 & 136 & 95.8 \\
\hline & ORLK511 & 170 & 82.5 & 35 & 16.9 & 1 & 0.5 & - & - & 182 & 88.4 & 24 & 11.7 & 90 & 43.7 & 116 & 56.3 \\
\hline & EDFM523 & 125 & 85.6 & 18 & 12.3 & 3 & 2.1 & - & - & 133 & 91.1 & 13 & 8.9 & 70 & 47.9 & 76 & 52.1 \\
\hline & ORAK521 & 128 & 83.7 & 20 & 13.1 & 5 & 3.3 & - & - & 153 & 100.0 & - & - & 29 & 18.9 & 124 & 81.1 \\
\hline & HIVA521 & 161 & 87.0 & 22 & 11.9 & 2 & 1.1 & - & - & 174 & 94.1 & 11 & 5.9 & 26 & 14.1 & 159 & 85.9 \\
\hline & LSIE518 & 107 & 76.4 & 32 & 22.9 & 1 & 0.7 & - & - & 123 & 87.9 & 17 & 12.1 & 35 & 25.0 & 105 & 75.0 \\
\hline & & 1551 & & 321 & & 29 & & 0 & & 1767 & & 134 & & 428 & 22.5 & 1473 & 77.5 \\
\hline
\end{tabular}


Table 8. Two-Way Table of the Number of Students Who Attended Contact Classes and Vacation Schools Within the ACE-Program Foundation Phase, and Who Wrote Examination During October 2009

\begin{tabular}{|c|c|c|c|c|c|c|c|c|c|c|c|c|c|c|c|c|c|}
\hline & \multicolumn{8}{|c|}{ Contact class attendance } & \multicolumn{4}{|c|}{ Vacation school attendance } & \multicolumn{4}{|c|}{ Pass / fail } \\
\hline & & \multicolumn{2}{|c|}{$\begin{array}{l}\text { No contact } \\
\text { class }\end{array}$} & \multicolumn{2}{|c|}{$\begin{array}{l}1 \text { contact } \\
\text { class }\end{array}$} & \multicolumn{2}{|c|}{$\begin{array}{c}2 \text { contact } \\
\text { classes }\end{array}$} & \multicolumn{2}{|c|}{$\begin{array}{l}3 \text { contact } \\
\text { classes }\end{array}$} & \multicolumn{2}{|c|}{$\begin{array}{l}\text { No vacation } \\
\text { school }\end{array}$} & \multicolumn{2}{|c|}{$\begin{array}{c}\text { Vacation } \\
\text { school }\end{array}$} & \multicolumn{2}{|c|}{$\begin{array}{l}\text { Fail final module } \\
\text { mark }<50\end{array}$} & \multicolumn{2}{|c|}{$\begin{array}{c}\text { Pass final module } \\
\text { mark }>50\end{array}$} \\
\hline \multirow{9}{*}{ 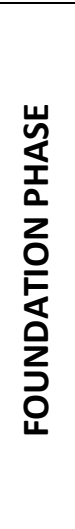 } & MODULES & $\mathbf{n}$ & $\%$ & $\mathbf{n}$ & $\%$ & $\mathrm{n}$ & $\%$ & $\mathrm{n}$ & $\%$ & $\mathbf{n}$ & $\%$ & $\mathrm{n}$ & $\%$ & $n$ & $\%$ & $n$ & $\%$ \\
\hline & ORAK511 & 202 & 71.9 & 76 & 27.1 & 3 & 1.1 & - & - & 235 & 83.6 & 46 & 16.4 & 61 & 21.7 & 220 & 78.3 \\
\hline & FSET511 & 235 & 77.1 & 64 & 20.9 & 6 & 1.9 & - & - & 261 & 85.6 & 44 & 14.4 & 86 & 28.2 & 219 & 71.8 \\
\hline & EUCE511 & 202 & 80.5 & 47 & 18.7 & 2 & 0.8 & - & - & 246 & 98.0 & 5 & 1.9 & 8 & 3.2 & 243 & 96.8 \\
\hline & ORLK511 & 237 & 82.0 & 47 & 16.3 & 5 & 1.7 & - & - & 242 & 83.7 & 47 & 16.3 & 101 & 34.9 & 188 & 65.1 \\
\hline & FROL571 & 121 & 72.5 & 40 & 23.9 & 6 & 3.6 & - & - & 166 & 99.4 & 1 & 0.6 & 17 & 10.2 & 150 & 89.8 \\
\hline & FROF571 & 154 & 75.5 & 48 & 23.5 & 1 & 0.5 & 1 & 0.5 & 204 & 100.0 & - & - & 58 & 28.4 & 146 & 71.6 \\
\hline & FROG571 & 129 & 77.3 & 36 & 21.6 & 1 & 0.6 & 1 & 0.6 & 166 & 99.4 & 1 & 0.6 & 37 & 22.2 & 130 & 77.9 \\
\hline & & 1280 & & 358 & & 24 & & 2 & & 1520 & & 144 & & 368 & 22.1 & 1296 & 77.9 \\
\hline & & & & & $0.1 ;$ & $0=0$. & 82 & & & & $=0.2$ & $p=0$. & & & $=0.3$ & $p=0.0$ & \\
\hline
\end{tabular}


Table 9. Two-Way Table of the Number of Students Who Attended Contact Classes and Vacation Schools Within the ACE-Program Geography, and Who Wrote Examination During October 2009

\begin{tabular}{|c|c|c|c|c|c|c|c|c|c|c|c|c|c|c|c|c|c|}
\hline & \multicolumn{8}{|c|}{ Contact class attendance } & \multicolumn{4}{|c|}{ Vacation school attendance } & \multicolumn{4}{|c|}{ Pass / fail } \\
\hline & & \multicolumn{2}{|c|}{$\begin{array}{l}\text { No contact } \\
\text { class }\end{array}$} & \multicolumn{2}{|c|}{$\begin{array}{l}1 \text { contact } \\
\text { class }\end{array}$} & \multicolumn{2}{|c|}{$\begin{array}{c}2 \text { contact } \\
\text { classes }\end{array}$} & \multicolumn{2}{|c|}{$\begin{array}{l}3 \text { contact } \\
\text { classes }\end{array}$} & \multicolumn{2}{|c|}{$\begin{array}{l}\text { No vacation } \\
\text { school }\end{array}$} & \multicolumn{2}{|c|}{$\begin{array}{c}\text { Vacation } \\
\text { school }\end{array}$} & \multicolumn{2}{|c|}{$\begin{array}{l}\text { Fail final module } \\
\text { mark }<50\end{array}$} & \multicolumn{2}{|c|}{$\begin{array}{c}\text { Pass final module } \\
\text { mark }>50\end{array}$} \\
\hline \multirow{14}{*}{ 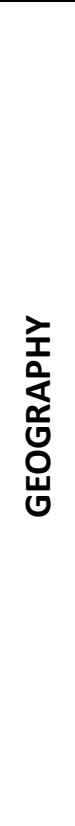 } & MODULES & $\mathrm{n}$ & $\%$ & $\mathbf{n}$ & $\%$ & $\mathbf{n}$ & $\%$ & $\mathrm{n}$ & $\%$ & $\mathrm{n}$ & $\%$ & n & $\%$ & $\mathbf{n}$ & $\%$ & $\mathbf{n}$ & $\%$ \\
\hline & ORAK511 & 4 & 66.7 & 2 & 33.3 & - & - & - & - & 5 & 83.3 & 1 & 16.7 & - & - & 6 & 100.0 \\
\hline & FSET511 & 7 & 58.3 & 5 & 41.7 & - & - & - & - & 11 & 91.7 & 1 & 8.3 & 3 & 25.0 & 9 & 75.0 \\
\hline & EUCE511 & 5 & 50.0 & 5 & 50.0 & - & - & - & - & 10 & 100.0 & - & - & - & - & 10 & 100.0 \\
\hline & ORLK511 & 6 & 75.0 & 2 & 25.0 & & & & & 8 & 100.0 & - & - & 1 & 12.5 & 7 & 87.5 \\
\hline & EDFM523 & 2 & 100.0 & - & & & & & & 2 & 100.0 & - & - & 2 & 100.0 & - & - \\
\hline & GBGK511 & 8 & 100.0 & - & & & & & & 8 & 100.0 & - & - & 4 & 50.0 & 4 & 50.0 \\
\hline & GSGK511 & 7 & 100.0 & - & - & - & - & - & - & 7 & 100.0 & - & - & - & - & 7 & 100.0 \\
\hline & GKLK521 & - & - & - & - & - & - & - & - & - & - & - & - & - & - & - & - \\
\hline & GGGK521 & - & - & - & - & - & - & - & - & - & - & - & - & - & - & - & - \\
\hline & ORAK521 & - & - & - & - & - & - & - & - & - & - & - & - & - & - & - & - \\
\hline & ORLK521 & - & - & - & - & - & - & - & - & - & - & - & - & - & - & - & - \\
\hline & HIVA521 & - & - & - & - & - & - & - & - & - & - & - & - & - & - & - & - \\
\hline & & 39 & & 14 & & 0 & & 0 & & 51 & & 2 & & 10 & 18.9 & 43 & 81.1 \\
\hline & & \multicolumn{4}{|c|}{$V=0.3$} & \multicolumn{4}{|c|}{$p=1.0000$} & \multicolumn{2}{|c|}{$V=0.2 ;$} & \multicolumn{2}{|c|}{$p=1.0000$} & \multicolumn{4}{|c|}{$p=0.55178$} \\
\hline
\end{tabular}




\section{Discrepancies Between Contact Class and Vacation School Attendance for Modules within the Four ACE-Programs}

Cramer's effect sizes (V) were calculated using two-way tables (Tables 6 to 9) in order to search for practical significant discrepancies, if any, between the contact class and vacation school attendance for modules within each of the four ACE-programs. Small effect sizes were found between the contact class attendance for modules with the ACE-programs Mathematics Education ( $V=0.1 ; p=0.0000)$, Learner Support $(V=0.1 ; p=0.00001)$ and Foundation Phase $(\mathrm{V}=0.1 ; \mathrm{p}=0.99982)$, which indicate small discrepancies between the contact class attendance of modules within these programs. A medium effect size $(V=0.3 ; p=1.000)$, which tends towards a practically significant discrepancy, was found between the contact class attendance for modules within the ACE-program Geography. For example, all students (100\%) did not attend any contact classes for the modules EDFM523, GBGK511 and GSGK511, while $75 \%$ of students did not attend any contact classes for the module ORLK511, appose to $50 \%$ who did not attend any contact classes for the module EUCE511. Furthermore, small effect sizes were found between the vacation school attendances for modules in all four programs, i.e. Mathematics Education: $V=0.2, p=0.0000$ (Table 6); Learner Support: $V=0.2, p=0.00001$ (Table 7); Foundation Phase: $V=0.2, p=0.0000$ (Table 8); and Geography: $V=0.2, p=1.0000$ (Table 9), which indicate no practically significant discrepancies between the vacation school attendance for modules within the four ACE=programs.

\section{Discrepancies between Students' Academic Success (Pass/Fail) for Modules within the Four ACE-Programs}

Table 6 indicates, per module, students' academic success (pass / fail) within the ACE-program Mathematics Education for the October 2009 examination. The mean pass percentage for all modules in this program is $76.1 \%$. Cramer's effect size (V) was calculated to search for practically significant discrepancies between students' academic success (pass / fail) for modules within this program. A medium effect $(V=0.3 ; p=0.0000)$ was found that indicates a statistically significant discrepancy, which tends towards practically significance. For example, the mean pass percentage for NDWK522 is $94.2 \%$ against only $5.8 \%$ who fail, and the pass percentage for EUCE511 is $97 \%$ against only $2.9 \%$ who fail. In contrast with these findings, the mean pass percentage for EDFM523 is $60 \%$ with a $40 \%$ fail percentage, and the mean pass percentage for NWPK522 is $55.3 \%$ with a $44.7 \%$ fail percentage. These discrepancies in academic success account for the medium effect size $V=0.3$.

Table 7 indicates, per module, students' academic success (pass / fail) within the ACE-program Learner Support for the October 2009 examination. The mean pass percentage for all modules in this program is $77.5 \%$. The highest pass percentage (95.8\%) was attained for LSDL528 and the lowest for EDFM523 (52.1\%). Cramer's effect size (V) was calculated to search for practically significant discrepancies between students' academic success (pass / fail) for modules within this program. A medium effect $(V=0.3 ; p=0.0000)$ was found that indicates a statistically significant discrepancy, which tends towards practically significance. For example, the mean pass percentage for LSDL528 is $95.8 \%$ against only $4.2 \%$ who fail. In contrast with these findings, the mean pass percentage for EDFM5123 is $52.1 \%$ against $47.9 \%$ who fail. Such discrepancies in academic success account for the medium effect size $V=0.3$. 
Table 8 indicates, per module, students' academic success (pass / fail) within the ACE-program Foundation Phase for the October 2009 examination. The mean pass percentage for all modules in this program is $77.9 \%$, which is very high despite low contact class attendance. Cramer's effect size (V) was calculated to search for practically significant discrepancies between students' academic success (pass / fail) for modules within this program. A medium effect ( $V=0.3 ; p=0.0000$ ) was found that indicates a statistically significant discrepancy, which tends towards practically significance. For example, the mean pass percentage for EUCE511 is $96.8 \%$ against only $3.2 \%$ who fail. In contrast with these findings, the mean pass percentage for ORLK511 is $65.1 \%$ against $34.9 \%$ who fail. Such discrepancies in academic success account for the medium effect size $V=0.3$.

Lastly, Table 9 indicates, per module, students' academic success (pass / fail) within the ACEprogram Geography for the October 2009 examination. The mean pass percentage for all modules in this program is $81.1 \%$, which is very high despite low contact class attendance. Cramer's effect size (V) was calculated to search for practically significant discrepancies between students' academic success (pass / fail) for modules within this program. A large effect ( $V=0.6 ; p=0.55178)$ was found between the academic success of modules within this program. For example, three modules (ORAKJ511, EUCE511 and GSGK511) have a 100\% pass percentage, against a pass percentage of 50\% for GBGK511 and 75\% for FSET511.

\section{Correlations between Academic Success (Final Module Marks) and Contact Class and Vacation School Attendance}

Spearman's rank-order correlations $(r)$ were computed to search for significant correlations between academic success (final module marks) and contact class and vacation school attendance.

Table 10. Spearman's rank-order correlations ( $r$ ) computed between academic success (final module marks) and contact class and vacation school attendance

\begin{tabular}{|l|c|c|}
\cline { 2 - 3 } \multicolumn{1}{c|}{} & Contact class attendance & Vacation school attendance \\
\hline $\begin{array}{l}\text { Academic success } \\
\text { (final module marks) }\end{array}$ & $\begin{array}{c}\mathrm{r}=0.04 \\
\text { No practically significant } \\
\text { correlation }\end{array}$ & $\begin{array}{c}\text { No practically significant } \\
\text { correlation }\end{array}$ \\
\hline Contact class attendance & & $\begin{array}{c}r=0.14 \\
\text { No practically significant } \\
\text { correlation }\end{array}$ \\
\hline
\end{tabular}

As seen in Table 10, no practically significant correlations $(r \geq 0.5)$ were found between contact class and vacation school attendance and the academic success (final module marks) of students. A possible reason why no practically significant correlations were found between academic success and contact class and vacation school attendance is the fact that the vast majority of students who perform well in their modules did not attend any contact classes or the vacation school. These students may feel that they do not need any study support in the form of contact classes and a vacation school. Satisfactory academic success (final marks) thus correlates more strongly with no contact class attendance and therefore overshadows the 
possible effect that contact class attendance may have on the academic success of certain students (the effect is thus cancelled out by the larger data pool). One should also consider the fact that the percentage frequency of students who attended contact classes for various modules (18.9\%) represents only a small portion (about one fifth) of the total sample. Therefore, contact class attendance will unlikely show a practically significant effect on academic success in the current investigation. Also included in Table 6 for interest sake, no practically significant correlation was found between contact class attendance and vacation school attendance. This indicates that the majority of students who attended contact classes for specific modules did not attend the vacation school for the same modules.

Table 11. One-Way ANOVA Correlation between Academic Success (Final Module Marks) and an Increase in the Number of Contact Class Attendance

\begin{tabular}{|c|c|c|c|c|c|c|c|c|}
\hline \multicolumn{4}{|c|}{0 to 4 contact classes attended } & \multicolumn{4}{|c|}{5 contact classes attended } & \multirow[b]{2}{*}{$\begin{array}{l}\text { Cohen's } \\
\text { effect size } \\
\text { (d) }\end{array}$} \\
\hline $\begin{array}{l}\text { Number } \\
\text { of } \\
\text { contact } \\
\text { classes } \\
\text { attended }\end{array}$ & $\mathbf{n}$ & $\begin{array}{c}\text { Mean } \\
\text { (academic } \\
\text { success) }\end{array}$ & $\begin{array}{c}\text { Standard } \\
\text { deviation } \\
\text { (academic } \\
\text { success) }\end{array}$ & $\begin{array}{l}\text { Number of } \\
\text { contact } \\
\text { classes } \\
\text { attended }\end{array}$ & $\mathbf{n}$ & $\begin{array}{c}\text { Mean } \\
\text { (academic } \\
\text { success) }\end{array}$ & $\begin{array}{c}\text { Standard } \\
\text { deviation } \\
\text { (academic } \\
\text { success) }\end{array}$ & \\
\hline 0 & 3999 & 56.27 & 15.07 & 3 & 3 & 63.67 & 15.04 & 0.5 \\
\hline 1 & 864 & 58.28 & 13.43 & 3 & 3 & 63.67 & 15.04 & 0.4 \\
\hline 2 & 65 & 56.11 & 15.15 & 3 & 3 & 63.67 & 15.04 & 0.5 \\
\hline
\end{tabular}

In order to establish if it was more beneficial for students' academic success to attend three contact sessions rather than one, two or no contact sessions, a one way ANOVA association analysis was performed to search for practically significant discrepancy (Cohen's effect sizes) between three contact session attendance against one, two and no contact sessions attendance. As reported in Table 11, a medium effect $(d=0.5)$, which tends towards a practically significant discrepancy, was found between three contact session attendance against two contact session attendance; while only a small effect $(d=0.36)$, indicative of a statistically significant discrepancy, was found between three contact session attendance and one contact session attendance. A medium effect $(d=0.5)$, which tends towards a practically significant discrepancy, was also found between three contact session attendance and no contact session attendance. These findings suggest it was beneficial for students in the current investigation to rather attend three contact sessions than two or no contact sessions. However, one should be cautious to generalize these findings because they pertain to the current research sample which reports low contact class attendance.

\section{Conclusions and Recommendations}

The results show that the majority of students in the current study did not attend any contact sessions or vacation schools. During 2009, the SCTE presented a total of 12 contact classes and two vacation schools at various contact centers throughout South Africa. This study compared the final marks of modules in which students wrote examination papers during October 2009 with the six contact classes and one vacation school presented prior to the examinations during the period April to September 2009. The average contact session attendance rate $(18.9 \%)$ and vacation school attendance rate $(7.97 \%)$ for various modules in which students wrote examination papers are very low. Also, no practically significant correlations were detected between contact session and vacation school attendance and the academic success (final marks) of students. In the light of these findings, as well as the high monetary 
commitment that the presentation of contact sessions entails, SCTE management should consider presenting a lesser number of contact classes. This study recommends that the focus of contact sessions should shift to modules in which students experience the most problems, i.e. modules with the lowest academic success rate, rather than facilitating all modules at contact classes. The practical implication is that the total number of contact classes (twelve) could be changed to only nine contact classes, in which problematic modules are presented, with four additional contact classes in which the rest of the program modules are presented.

A further recommendation is that the duration of vacation schools, currently presented on one Saturday per vacation school, are extended with one or two days, for many students refrain from travelling large distances to attend vacation schools on Saturdays because of family and school related responsibilities. If vacation schools were longer, more students would possibly attend vacation schools for the opportunity to have longer contact with lecturers, and less would possibly attend the contact sessions presented by facilitators.

It seems that the academic success of students in this study should rather be ascribed to another variable, e.g. effective study material, than contact class attendance. The fact that the majority of academically successful students did not attend any contact classes, clearly points towards effective study material (i.e. study letters, study guides, DVDs and examination information) which supports ODL students in rural areas to achieve academic success.

The final conclusion and recommendation of this investigation is that besides contact classes, more attention should be given to the implementation of e-learning as another tool for ODL program delivery. If the majority of students develop basic computer comperacy, and all schools and study centers have computer and Internet facilities available to students, elearning could easily become the main delivery tool for ODL students in South Africa. However, currently socio-economic factors such as poverty, low literacy, under-qualification and low comperacy still halter the full implementation of e-learning in the South African higher education sector (Blignaut \& Els, 2010). Also, m-learning (mobile learning) is increasingly being used in the African context for teaching and learning - a tool already used by the SCTE for generic text communication (e.g. examination information) to students, as well as for the provision of certain study material via a newly implemented mobi-site.

\section{References}

Bernard, R. M., Abrami, P. C., Lou, Y., Borokhovski, E., Wade, A., Wozney, L., et al. (2004). How does distance education compare with classroom instruction? A meta-analysis of the empirical literature. Review of Educational Research, 74(3), 379-439.

Blignaut, A. S. \& Els, C. J. (2010). Comperacy assessment of postgraduate students' readiness for higher education. Internet and Higher Education, 13, 101-107.

Burrell, G., \& Morgan, G. (1979). Sociological paradigms and organisational analysis. Brookfield: Ashgate.

Deka, T. S. \& McMurry, P. (2006). Student success in face-to-face and distance teleclass environments: A matter of contact? International Review of Research in Open and Distance Learning, 7(1), 16.

Delling, R. M. (1987). Towards a theory of distance education. ICDE Bulletin, 13, 21-25. 
Edwards, R. (1995). Different discourses, discourses of difference: Globalisation, distance education and open learning. Distance Education, 16(2), 241-255.

Holmberg, B. (1986). Growth and structure of distance education. London: Croom Helm.

Hui, P., Crowcroft, J., \& Yoneki, E. (2008). Bubble Rap: Social-based forwarding in delay tolerant networks. Paper presented at the 9th ACM international symposium on Mobile ad hoc networking and computing. http://reality.media.mit.edu/pdfs/Hui08_2.pdf

International Monetary Fund. (2011). World Economic Outlook (WEO) Report - Tensions from the two-speed recovery: Unemployment, commodities and capital flows. Washington: International Monetary Fund.

Jahng, N., Krug, D., \& Zhang, Z. (2007). Student achievement in online distance education compared to face-to-face education. Retrieved 8 October, 2010, from http://www.eurodl.org/materials/contrib/2007/Jahng_Krug_Zhang.htm

Lobel, M. \& Neubauer, M. (2005). Selected topics from a matched study between a face-toface section and a real-time online section of a university course. International Review of Research in Open and Distance Learning, 6(2), 1-17.

Pandor, N. (2004). Promoting quality in state schools (Speech delivered by former Minister of Education at the Boys Only Principal Conference, 25 August 2004, Rondebosch) Retrieved 22 February, 2010, from http://www.info.gov.za/speeches/2004/ 04083013451002.htm

Picciano, G. (2000). Distance learning: Making connections across virtual space and time. Upper Saddle: Merrill Prentice Hall.

Schlosser, L. A. \& Simonson, M. (2002). Distance education: Definition and glossary of terms. Bloomington: Association for Educational Communications and Technology.

Shachar, M. (2008). Meta-Analysis: The preferred method of choice for the assessment of distance learning quality factors. International Review of Research in Open and Distance Learning, 9(3), 1-15.

Simpson, O. (2002). Supporting students in online, open and distance learning. New York: Routledge.

Solimeno, A., Mebane, M. E., Tomai, M., \& Francescato, D. (2008). The influence of students and teachers characteristics on the efficacy of face-to-face and computer supported collaborative learning. Computers \& Education, 51(109-128).

SPSS. (2007). SPSS ${ }^{\circledR} 16.0$ for Window, Release 16.0.0 Retrieved 18 February, 2010, from http://www.spss.com/

Taylor, D. (2006). Issues, trends, and challenges in distance education: An international perspective. Retrieved 12 October, 2010, from http://next.eller.arizona.edu/courses/ InternationalManagement/Fall2006/student_papers/final_papers/Distance_Learning.pd $f$ 
United Nations Educational Scientific and Cultural Organization. (2002, ). Open and distance learning: Trends, policy and strategy considerations. Retrieved 18 February, 2010, from http://unesdoc.unesco.org/images/0012/001284/128463e.pdf

Van Zyl, M. J. \& Spamer, E. J. (2010). Distance education programmes for the upgrading of teachers' qualifications in South Africa: The effect of contact class attendance on pass rates. Paper presented at the Hawaii International Conference on Education, 7-10 January 2010, Honolulu, Hawaii.

Watkins, B. L. (1991). A quite radical idea: Invention and elaboration of collegiate correspondence study. In B. L. Watkins \& S. J. Wright (Eds.), The foundations of American distance education (pp. 1-35). Dubuque: Kendall / Hunt.

Correspondence: Christo J. Els, School of Continuing Teacher Education, North-West University, Potchefstroom, North-West Province, South Africa 